\title{
O DADO DAS EMPRESAS: POSSÍVEIS EFEITOS DE SENTIDO DE UMA TRADUÇÃO INTERSEMIÓTICA DA ARTE DE AMAR DE CHIARA LUBICH ${ }^{1}$
}

\author{
COMPANY CUBE: POSSIBLE MEANING EFFECTS OF AN INTERSEMIOTIC \\ TRANSLATION OF CHIARA LUBICH'S ART OF LOVING.
}

Verônica Braga Birello

Universidade Estadual de Maringá-UEM

Ana Paula Pinheiro da Silveira

Universidade Tecnológica Federal do Paraná- UTFPR

RESUMO: A expansão do pensamento de Lubich, fundadora do movimento dos Focolares, impulsionou seus seguidores a compreenderem como traduzir as suas ideias de modo que fossem sempre mais conhecidas, adaptadas às diversas culturas e grupos. Nessa perspectiva, o Dado do amor, voltado ao público infantil, pode ser compreendido como um exemplo de tradução intersemiótica do livro a Arte de Amar. A partir da ideia do dado do Amor muitos outros foram criados para serem utilizados em diversos contextos. Neste estudo analisaremos as faces do dado das Empresas e suas explicações propostas por Mundell (2014) em comparação com os textos (escritos e orais) de Lubich (2017) sobre a Arte de Amar e as faces do Dado do amor. Por meio dessa análise, buscaremos entender quais os deslocamentos promovidos por essa tradução bem como as repetições de sentido que são reafirmados por meio da mudança de meio de circulação desse discurso. O aporte teórico deste estudo se fundamenta nos estudos epistemológicos da tradução como Plaza (2010) e Lefevere (2007) e da Análise do Discurso francesa e seus desdobramentos no Brasil como Pechêux (1995) e Orlandi (2009).

PALAVRAS-CHAVE: Chiara Lubich, Tradução intersemiótica, Análise do Discurso, Focolares, Dado das Empresas.

ABSTRACT: The broadening of Lubich's ideas, foundress of the Focolare movement, impelled her followers towards the understanding of how to translate these thoughts so that they would be better known and adaptable to different cultures and groups. From this perspective, the Dice of Love, which were developed to children, can be understood as an example of intersemiotic translation of the book the Art of Loving. From the idea of the Dice of Love other dices were created to be used in different contexts. In this study we will

1 Submetido em 10/10/2020 - Analisado em 26/11/2020 
analyze the faces of the Company Cube and its explanations proposed by Mundell (2014) in comparison with the texts (written and oral) of Lubich (2017) on the Art of Loving and the faces of the Dice of Love. Through this analysis, we will seek to understand the displacements promoted by this translation as well as the repetitions of meaning that are reaffirmed by changing the means of circulation of this discourse. The theoretical contribution of this study is based on the epistemological studies of translation such as Plaza (2010) and Lefevere (2007) and the French Discourse Analysis and its developments in Brazil such as Pechêux (1995) and Orlandi (2009).

Keywords: Chiara Lubich, Intersemiotic Translation, Discourse Analysis, Focolares, Company Cube.

\section{INTRODUÇÃO}

A tradução é uma constante no movimento dos Focolares, uma vez que, além de ser mundialmente conhecido, está presente de forma atuante em mais de cento e oitenta nações, o que desde o seu início propiciou que a produção de Lubich fosse traduzida nas mais diversas línguas. Além disso, o movimento fundado por Chiara Lubich não se limita ao aspecto religioso, espiritual, mas pode ser compreendido como um sistema de valores e de crenças, portanto, estudado no âmbito cultural ao qual aderem crianças, adolescentes, jovens, adultos e idosos. Dessa forma, como compreende uma variedade de pessoas, de faixas etárias, de grupos sociais, ao acessar a página do movimento na internet é possível encontrar os temas da cultura, do diálogo ecumênico e inter-religioso, da arte, do esporte, da economia, da mídia e da comunicação, do direito, em suma, são muitos e variados. Também se compreende que há questões que estão sendo discutidas hoje e que podem ser analisadas no futuro à luz do pensamento de Lubich, o que torna a tradução algo constante. Isso porque a tradução não se realiza apenas entre línguas, mas também entre temas que precisam ser pensados e enunciados de uma nova forma, para essa área em particular.

O amor está no centro do pensamento de Lubich. Em uma edição mais recente de seu livro, A Arte de amar, partindo do conceito do amor no cristianismo, defende que esse deve se estender às diferentes religiões ou a pessoas sem referência religiosa. Isto porque se o amor é entendido como arte, como esta deve ser para todos.

Traduzir o conceito da arte de amar, explicitado por Lubich (2017), de forma mais ampla, com categorias que pudessem estar presentes, por exemplo, no âmbito da família, do trabalho, no escritório, na empresa, na fábrica, impulsionaram um grupo do movimento dos Focolares a mobilizar esforços para realizar uma tradução intersemiótica que possibilitasse tornar os conceitos presentes no discurso de Lubich operacionalizáveis 
e sintetizados em enunciados curtos. Dentre as diversas propostas adaptadas a diferentes contextos está o objeto desse nosso estudo.

Este artigo tem como proposta analisar o processo da formação de sentidos quando Mundell (2014) traduz a partir de Lubich (2017) e obtém como resultado o Dado das Empresas. Nosso material de análise, portanto, serão os pontos elencados por Chiara Lubich (2017) como basilares da Arte de amar e as faces do Dado das Empresas proposta por Mundell (2014). Entendemos que os enunciados ao serem mobilizados pela tradução podem provocar diferentes efeitos de sentido, deslocamentos, repetições, buscaremos saber de que forma isso se dá. Visando atingir o nosso objetivo, tomaremos como base do percurso analítico a teoria da Análise do Discurso, (AD), da linha Pecheutiana francesa e os seus desdobramentos no Brasil.

\section{A FUNÇÃO DA TRADUÇÃO ENTRE DIFERENTES MEIOS}

Primeiramente, é importante marcar nosso lugar de enunciação ao falar de tradução, porque, embora seja uma área de estudo já bastante consolidada, há muitas vertentes diferentes. Jakobson (2000) propõe que a tradução pode ser intralinguística, interlinguística ou intersemiótica. Contudo, quando o autor faz esta divisão, chama de tradução propriamente dita apenas a tradução interlinguística ou seja, a que resulta da manipulação de dois sistemas linguísticos diferentes, tornando o texto numa língua de origem compreensível para uma língua diferente no texto de destino. Portanto, aquilo a que Jakobson (2000) chama tradução intralinguística e intersemiótica não estariam no mesmo nível de importância que a "tradução". Contudo, Derrida (2002) explica que não deve haver uma noção de valor entre estas atividades, pois como poderia ser uma "própria" e a outra "figurativa"? Uma vez que também acreditamos que diferentes formas de tradução são sempre traduções, abordaremos a nomenclatura proposta por Jakobson (2000) neste trabalho não pensando nessa questão valorativa que mencionamos e sim porque o material de análise trata de uma mudança de materialidade: a passagem do texto verbal no suporte livro para o texto verbal em suporte dado - jogo.

Quando pensamos em tradução, assumimos que não se trata de escrever, mas de reescrever, assim, quem ocupa o primeiro plano não é quem escreveu ou enunciou, mas quem reescreveu. Lefevere (2007) chama os tradutores de corresponsáveis pela recepção dos trabalhos, e tal como Benjamin (2008) afirma que são os tradutores os responsáveis pela sobrevivência da obra. No entanto, é de notar que esta divisão de responsabilidades não torna o tradutor menor. Este tema é importante para este trabalho, uma vez que a tradução da Arte de Amar de Lubich (2017) por Mundell (2014) promove a recepção geral destes princípios em sua circulação, uma vez que foi concebida para o ambiente organizacional. 
Além disso, como se trata de uma tradução intersemiótica, ou na nomenclatura utilizada por Clüver (2006) intermídia, é preciso pensar a tradução que foi realizada para circular neste suporte - o dado.

Sem perder de vista o nosso material de análise, o Dado das Empresas, percebemos que seria necessário pensar de uma forma multidisciplinar. Sabemos que neste caso, o tradutor é de fato um empresário e não um tradutor de formação ou profissão, ainda que Mundell (2014) parta de um objetivo muito claro, trazer a Arte de Amar de Chiara Lubich (2017) para as organizações empresariais. Dito isto, acreditamos que o material também pode ser pensado à luz da teoria funcionalista da tradução, uma vez que os autores Polchlopek, Zilpser, \& Costa (2012, p. 23) explicam que “ (...) ser funcional significa responder (de alguma maneira) às necessidades (comunicativas, sociais, matemáticas) de outra pessoa ou situação". Assim, numa tradução funcionalista, leva-se em conta a utilização prática da tradução: o que se pretende provocar com esta afirmação; porque, ou a razão pela qual se pretende transmitir tal mensagem; como, de que forma é possível dizer e, finalmente, a quem, ou seja, que público se pretende atingir com esta tradução. Obviamente, não é possível entrar na mente de Mundell (2014) para obter tais respostas, e mesmo que o tenhamos entrevistado, nesse momento é muito mais importante para nós compreender como a sua tradução funciona nestes aspectos mencionados, do que compreenderem as suas pretendidas intenções na tradução. Isso porque, por causa da perspectiva discursiva, não é a autoria que conta, mas o funcionamento discursivo dos enunciados.

A tradução vista de uma perspectiva funcionalista não busca a "fidelidade" ao texto "original", mas sim um compromisso com o contexto e a sua ação comunicativa. Nord (1996) explica que a tradução deve ser pensada a partir dos skopos, ou seja, a partir de um objetivo, que torna o texto alvo independente do texto fonte. E isso é importante para nós porque compreendemos que o Dado das Empresas, sendo uma tradução, é o mesmo e outro texto, ao mesmo tempo e que aparece noutra materialidade - o dado, ou mesmo um aplicativo ou website. Através deste texto que é outro e o mesmo, os sujeitos podem construir significados que também podem ser os mesmos ou outros.

Além disso, entendemos ser preciso voltar ao termo já mencionado da tradução intersemiótica, embora não estejamos falando apenas do texto e sim de um deslocamento de materialidades, quando os escritos de Lubich (2017) passam a circular nas faces de um objeto outro, um dado. Segundo Plaza (2010), os acontecimentos que envolvem sistemas de signos distintos podem ser caracterizados enquanto traduções intersemióticas. Para o autor, é preciso ter um olhar abrangente para a tradução intersemiótica, sem a pretensão de estabelecer limites para os diversos sistemas de signos, e isso nos permite olhar para o nosso objeto - um jogo, ou as faces de um dado. Plaza (2010) entende que há a passagem 
de signos linguísticos para não-linguísticos na tradução intersemiótica, o que torna nosso objeto de estudo deveras interessante pois, embora o apresentemos seguindo uma ordem, a dos pontos propostos no texto de partida, é interessante pensar que o leitor, ao ter contato com o objeto, irá vê-lo aos poucos, à medida em que o joga e tem contato com o texto em suas diferentes faces.

Além disso, é preciso dizer que, semioticamente, o objeto de nosso estudo seria a relação estabelecida entre os dois textos, contudo, há de se ater nas condições de produção e nas relações que elas estabelecem com os textos - fonte e de chegada. Isso porque estamos tratando de duas formações discursivas bem específicas neste trabalho: a do Movimento dos Focolares e a Empresarial. Nessa perspectiva, para nós é interessante pensarmos a relação do texto com essas relações, conforme defendido por Plaza (2010, p. 14):

\footnotetext{
Tradução como prática crítico-criativa na historicidade dos meios de produção re-produção, como leitura, como metacriação, como ação sobre estruturas eventos, como diálogo de signos, como síntese e reescritura da história. Quer dizer: como pensamento em signos, como trânsito dos sentidos, como transcriação de formas na historicidade.
}

Assim, entendemos também o material de estudo deste trabalho, uma tradução que resulta de uma prática transcriativa. Não obstante, há ainda uma questão a mencionar, a da cultura de chegada. Não devemos perder de vista o fato de que a tradução em questão está disponível para todos. No entanto, como Lefevere (2007) assinala, a tradução visa encontrar o seu lugar na cultura de chegada. Dito de outro modo, na cultura de chegada, a tradução deve corresponder ao horizonte de expectativa do leitor. Portanto, o que não podemos perder de vista é que a cultura de chegada é também a cultura do movimento dos Focolares em primeiro lugar. Lefevere (2007, p.150) diz a respeito da tradução: "Se ela não estiver em conformidade com as demandas do gênero que domina a cultura de chegada, sua recepção será provavelmente dificultada". Sendo assim, é importante compreender que se este material de análise não estivesse em conformidade com o que é a cultura de chegada, ou seja, o Movimento dos Focolares, provavelmente não teria sido difundido a todos dentro e fora do movimento. Desta forma, iremos aprofundar o conceito de condições de produção no próximo tópico.

\section{O DADO DAS EMPRESAS E A ARTE DE AMAR UM MOVIMENTO ANALÍTICO}

Tendo proposto algumas reflexões sobre o conceito de tradução, especialmente para esclarecer o nosso ponto de partida para a reflexão acerca deste material de análise, passaremos às questões que influenciam diretamente a Análise do Discurso. Como 
mencionado anteriormente, este trabalho propõe uma análise baseada nos estudos de Michel Pêcheux sobre a AD francesa e o seu desenvolvimento no Brasil.

Petri (2007, p. 40) propõe duas expressões-chave para pensar os estudos que se propõem realizar uma análise do discurso no Brasil: "A Análise de Discurso é uma disciplina de entremeio' e 'o dispositivo teórico-metodológico da Análise de Discurso se constrói num movimento pendular entre teoria e análise”. Assim, estas considerações de Petri (2007) ajudam-nos a explicar este desenvolvimento teórico que está sendo construído no Brasil. É também este "movimento pendular" que não nos permite engessar a análise neste artigo, ainda que possa causar algum estranhamento para leitores de outras áreas.

A nossa proposta aqui é pensar o nosso objeto através da lente discursiva que uma hora olha para o corpus, outra hora olha para a teoria. Assim, a proposta deste trabalho em termos de metodologia e procedimentos que iremos utilizar é também da $\mathrm{AD}$, que procura através do desenvolvimento de um dispositivo experimental e novo de análise para cada trabalho, construir cada análise, que se torna única, independentemente do retorno de declarações ou materiais. No entanto, Petri (2007, p. 41) adverte que esta metodologia, embora seja difícil descrever com precisão como outros métodos de análise linguística não é uma caracterização de uma não metodologia. Para obter possíveis reflexões é necessário, segundo o autor “(...) respeitar a teoria e, portanto, conhecer bem as noções teóricas e, portanto, poder mobilizar estas noções que constituem uma análise do discurso em questão". Assim, a metodologia de análise que pensamos utilizar neste trabalho se dá em constante movimento assim como a formação de sentidos, que é o que nos interessa Dito isto, aprofundaremos aqui o nosso material que será recortado em corpus: o livro A Arte de Amar de Chiara Lubich (2017) e num segundo momento O Dado das Empresas de Mundell (2014).

Dessa forma, definimos o nosso ponto de partida, os escritos que foram recolhidos sob o título $A$ arte de amar e que foram amplamente difundidos entre os membros do Movimento dos Focolares. Discursivamente, este livro funciona como um arquivo, (PECHEUX, 1990), um ponto de referência, o já dito sobre o assunto e cujos significados foram estabilizados. Dito de outra forma, os escritos de Lubich (2017) são imobilizados, o pêndulo repousa apenas sobre eles, mas quando temos um contato com o Dado das Empresas de Mundell (2014), há um impulso neste pêndulo outrora imóvel. Segundo a proposta da AD, faz-se necessário voltar o olhar noutra direção - a da tradução, e ao mesmo tempo este pêndulo terá de fazer o movimento de retorno e pensar na teoria discursiva, passando sempre por aquele ponto de apoio, até então estabilizado: A arte de amar.

Neste sentido, é possível dizer:

Os efeitos do movimento pendular nas "relações de sentido", enquanto vaivém entre discursos que promove a agregação e o desprendimento de sentidos, reiterando 
e transformando, via movimento. Instalado o gesto de ler do analista no interior da discursividade que lhe interessa analisar, temos o pêndulo no ponto zero e daí começa o movimento (PETRI, 2007, p. 47)

Assim, ao colocarmo-nos no espaço discursivo que ocupa, A arte de amar de Lubich (2017), de onde começamos o nosso movimento de análise, compreendemos que o amor está na base de todo o enunciado da autora. E que o conceito de arte do qual ela parte se baseia na mimese aristotélica, ou seja, uma arte que é ativa e que, por isso, cria, constrói. Sendo possível recorrer à teoria clássica, pode-se dizer que, para Aristóteles, a mimese é um traço distintivo do homem que pode fazer e refazer, ou nas palavras de Lubich (2017) recomeçar sempre. Assim, a realização artística da qual a autora nos fala é constante. Consideremos isto um possível impulso do pêndulo na análise a partir do conceito de interdiscurso, desenvolvido aqui por Orlandi (2009), que trata do pensamento, da memória, em relação à palavra. Assim, temos em movimento algo que fala primeiro, noutro lugar, independentemente, não uma memória empírica, mas uma memória social-discursiva, o que nos permite dizer que está na base do já dito e do dito. Lubich $(2017$, p. 26) explica que o amor cristão é uma arte e que cabe aos seres humanos todos, e não apenas aos cristãos, conhecerem esta arte, porque enquanto arte deve ser acessível a todos. Assim, o interdiscurso fornece afirmações que influenciam a forma como o assunto significa numa situação, e é isto que nos permite compreender o Dado das empresas proposto por Mundell (2014). O interdiscurso é de suma importância justamente por estarmos pensando nessa relação estabelecida pela tradução, visto que Plaza (2010) especifica que por se tratar da tradução semiótica de diferentes sistemas de signos as relações estabelecidas entre o sentido, o meio e o código são essenciais, dessa forma, o interdiscurso é para nós esse fluido em que estão imersas as relações.

O Dado das Empresas, proposto pelo empresário estadunidense John Mundell, em 2014, visava traduzir a Arte de amar de forma que pudesse ser aplicada e vivida diariamente dentro das pequenas empresas que eram geridas de acordo com os princípios da Economia de Comunhão ${ }^{2}$. De acordo com o empresário, seria uma forma de impactar positivamente a vida empresarial. Visto que o jogo - dado - já era uma realidade do Movimento dos Focolares, a medida em que Chiara usava o chamado Dado do Amor para explicar a arte de amar de forma prática às crianças, o empresário decidiu por fazer circular a sua tradução também em forma de jogo. O website do projeto ${ }^{3}$ conta com versões que podem ser baixadas e impressas resultando no objeto físico, conta ainda com a opção de "girar"

2 A Anpecon (Associação Nacional por uma Economia de Comunhão, explica que "A Economia de Comunhão (EdC) nasceu em maio de 1991 no Brasil, com o objetivo de colaborar com a redução da pobreza, através da organização de iniciativas econômicas inseridas dentro de um movimento cultural mais amplo, composto por pessoas e instituições que objetivam, dos mais diversos modos, individual e coletivamente, construir a fraternidade nos dias de hoje.". Disponível em: https://www.anpecom.com.br/economia-de-comunhao/

3 https://thecompanycube.org/pt-br/ 
o dado de forma online no próprio website e ainda um aplicativo para baixar no Google Play e na AppStore, que permite que o dado seja girado pelo smartphone.

Dentro deste mesmo espaço discursivo, Chiara Lubich (2017) afirma que a Arte de amar desencadeia uma revolução que Mundell (2014) também traz à luz em sua tradução, dizendo que o Dado das Empresas é "Uma nova revolução para pequenas empresas". Para o pensador, a revolução da arte de amar alcança e renova as várias expressões do ser humano, dessa forma, também no campo econômico, no campo empresarial, ou seja, o público-alvo da Mundell (2014). Neste sentido, retomamos o que diz Pêcheux (1990, p.9): "Portanto, se no espaço revolucionário tem-se a questão da passagem de um mundo a outro, a relação com o invisível é aí inevitavelmente colocada (...)”. A revolução de Lubich (2017) e Mundell (2014) também envolve esta passagem de um mundo para outro, partindo de um mundo em que não se vive a arte do amor para um mundo em que se vive. "Se somos todos irmãos e irmãs, devemos amar a todos. Devemos amar a todos. Parece uma coisa pequena de nada... mas é uma revolução (LUBICH, 2017, p. 33)”.

Pêcheux (1990, p.16), ao falar do processo revolucionário diz que uma das formas de pensa-lo seria:

(...) pressupor, no interior do mundo existente, a existência de um germe revolucionário independente, presente no estado prático como uma essência certamente entravada, reprimida, dominada, mas, no entanto, prestes a fazer irromper, toda armada como Atená, e a dominar, por sua vez quando chegar o dia.

Porque Lubich (2017) fala precisamente de um novo mundo. O filósofo francês diz que é preciso coragem, para que possamos criar um mundo diferente a partir de algum lugar. Por que não partir também do mundo empresarial? E todos podem fazer parte desta revolução, uma vez que a podem chamar filantropia, solidariedade, altruísmo, sem que adquira um caráter religioso. Por outro lado, pode ser principalmente cristã, no sentido de que é essa revolução que os primeiros cristãos trouxeram ao mundo, amando todos individual e coletivamente.

Considerando que estamos buscando compreender como a tradução da Arte de amar produz significados quando traduzida para o Dado das Empresas, compreendemos que tanto a autora quanto o tradutor partem do mesmo princípio: o da revolução. Agora, precisamos compreender como as faces do dado significam - o mesmo e de outras formas. Podemos, portanto, pensar, discursivamente, sobre os conceitos de paráfrases e polissemia, já que, segundo Orlandi (2009), é sempre um desafio compreender o que é o mesmo e o que é diferente. Discursivamente, portanto a linguagem, sobretudo para nós que também compreendemos explicitamente a tradução, funciona sempre na tensão entre estes dois processos: paráfrases e polissemia. Explica Orlandi: 
Os processos parafrásticos são aqueles pelos quais em todo dizer há sempre algo que se mantém, isto é, o dizível, a memória. A paráfrase representa assim o retorno aos mesmos espaços do dizer. Produzem-se diferentes formulações do mesmo dizer sedimentado. A paráfrase está do lado da estabilização. Ao passo que, na polissemia, o que temos é deslocamento, ruptura de processos de significação (ORLANDI, 2009, p.36).

Partindo do que já foi estudado, compreendemos que a tradução pode jogar com ambos os processos, mantendo ou mudando os significados. Portanto, a ideia de olhar atentamente para o nosso corpus de análise, questionando-nos sobre este caso específico, se o tradutor, ao traduzir intersemioticamente o objeto, evocava o mesmo ou outros sentidos. Isto porque, como já explicamos, não partimos de uma teoria estruturalista da tradução, aquela que visa "garantir" que o texto seja sempre o mesmo. Neste trabalho, pensamos que será sempre outro texto, ainda que filiado à mesma rede de significados. Em outras palavras, segundo Orlandi (2009), são forças que trabalham em conjunto neste já dito: o mesmo e o outro.

Assim, agora que o pêndulo analítico faz o seu regresso ao objeto, vamos nos ater aos pontos que Lubich (2017) enumera como parte da arte de amar: Amar a todos; Amar por primeiro; Amar como a si mesmo; Fazer-se um; Amar Jesus no outro; Amar reciprocamente. Estes seis pontos são, portanto, o nosso texto de partida. O nosso texto de chegada são as faces do dado apresentado por Mundell (2014) como se segue: Construir relacionamentos dia após dia; Compartilhar conhecimentos, tempo, você mesmo; Ser o primeiro a ajudar os outros; Ajudar com ações, não apenas palavras; Valorizar cada pessoa, cada ideia. Os concorrentes podem ser amigos também.

Discursivamente, nesta tensão entre polissemia e paráfrases, estamos na posição do leitor que, quando em contato com os enunciados, não considera só o que é dito, mas também o não-dito e que, também, significa. Portanto, por mais que, no início do nosso trabalho, tenhamos estabelecido que as faces do Dado das Empresas têm como texto fonte os escritos da Arte de amar, compreendemos no decorrer do trabalho que não poderíamos ignorar o dado do amor que Chiara Lubich utilizava para traduzir a Arte de Amar para crianças. E esta impossibilidade ocorre porque são estabelecidas relações de significado entre estes textos. Neste ponto, entendemos que os efeitos do significado que o texto promove são também constituídos pelos textos que a ele se referem (ORLANDI, 2008). Temos, portanto, a reflexão que Orlandi nos apresenta (2008, p. 20):

Expressa-se assim o conflito entre o garantido, o institucionalizado, o legitimado, e aquilo que, no domínio do múltiplo, tem de se garantir, se legitimar, se institucionalizar. A polissemia é o conceito que permite a tematização do deslocamento daquilo que na linguagem representa o garantido, o sedimentado. Esta tensão básica, vista na perspectiva do discurso, e a que existe entre o texto e o contexto histórico-social: porque a linguagem é sócio-historicamente constituída, ela muda; pela mesma razão, ela se mantém a mesma. Essa é a sua ambigüidade. 
O que seria a tradução se não fosse a língua? Como é possível mudar a língua e permanecer o texto o mesmo? Vemos que neste jogo se pode traduzir:

\author{
Amar a todos: Os concorrentes podem ser amigos também; \\ Amar por primeiro: Ser o primeiro a ajudar os outros; \\ Amar como a si mesmo: Compartilhar conhecimentos, tempo, você mesmo; \\ Fazer-se um: Valoriza cada pessoa, cada ideia; \\ Amar Jesus no outro: Ajuda com ações, não apenas com palavras; \\ Amar reciprocamente: construir relacionamentos dia após dia;
}

Temos a formação de famílias parafrásticas que significam, porque significa a escolha do tradutor por uma palavra e não outra, mesmo que seja questionado como sujeito. Vemos que a apropriação da língua do tradutor, Mundell (2014), não é individual, mas social porque suas escolhas só podem ser feitas dentro de uma condição de possibilidade, embora sejam muitas, não são infinitas, porque as condições são limitativas. Orlandi (2008) explica que cada discurso tem o seu ponto de partida num discurso anterior e indicará outro discurso futuro. Não é, portanto, um ponto, mas um continuum.

Considerando as faces do dado como uma tradução, tentamos partir de cada um dos pontos e encontrar quais foram os motivadores de cada uma das faces do dado. Assim, entendemos que o primeiro ponto: Amar a todos fora traduzido por Mundell (2014) como: Os concorrentes podem ser amigos também. Uma vez que, no mundo dos negócios, a concorrência é muitas vezes, vista como inimiga, portanto, a postura deve ser contrária ao amor. Ao dizer que os concorrentes também podem ser amigos, retoma-se a afirmação de uma das faces do Dado do amor que é Amar o inimigo. Assim, entendemos que as declarações regressam como acontecimentos, que têm um significado diferente e que ecoam em outros locais. Os pontos da espiritualidade da Arte do Amor e a sua tradução para o Dado do Amor são também transferidos para o Dado das Empresas.

Em seguida, Amar por primeiro na sua tradução torna-se Ser o primeiro a ajudar os outros. É possível entender que a mudança do verbo, amar para ajudar, signifique como uma tentativa de traduzir para uma atitude concreta o que seria o amor. Em um ambiente organizacional o amor é pensado de modo que pudesse ser expresso como ajuda, auxílio. O ponto da Arte de Amar que é expresso por Lubich (2017) da seguinte forma: Amar como a si mesmo passa a ser traduzido para como: Compartilhar conhecimento, tempo, você mesmo. Existe aqui, novamente, uma tentativa de expandir ou de explicar o significado do verbo amar, dentro de uma mesma formação discursiva que é a do amor. Esta seria uma possibilidade para entender o enunciado que circula na tradução. Afinal, dentro da 
formação discursiva do amor, é possível dizer que quem ama, demonstra por meio ações, não só palavras e dentro de empresa o que poderia ser partilhado? Talvez conhecimento, tempo, ou o que poderia ser entendido enquanto capital intelectual dos colaboradores.

O ponto da Arte de Amar descrito por Chiara Lubich (2017) como Fazer-se um é traduzido por Mundell (2014) como Valorizar cada pessoa, cada ideia. Pode-se pensar que quando nos fazemos um com o outro, ou quando nos colocamos no lugar da outra pessoa de forma empática estamos valorizando a pessoa como um ser humano, as suas ideias, o seu trabalho. Também identificamos que no enunciado do Dado do amor, utilizado com as crianças, uma vez que há uma face que propõe à criança amar o outro como a si mesma, porque da mesma forma, há um desejo de valorizar o outro como a si.

Não obstante, notamos que, no ponto Amar Jesus no outro, o tradutor encontra uma impossibilidade, a de mencionar Jesus. Isso não se dá no dado das crianças, porque, assim como a Arte de Amar de Lubich (2017) ele também fora pensado para as crianças pertencentes ao Movimento dos Focolares. Ainda que hoje se utilize o Dado do amor com crianças em vários ambientes como escolas e projetos sem caráter religioso, em sua origem Lubich o pensou para as crianças das novas gerações do movimento, dessa forma, Jesus pode fazer parte desse discurso. Agora, quando pensamos na função social do Dado das empresas, é preciso partir do pressuposto de que, em uma organização empresarial, uma diversidade de pessoas trabalham, juntas, com ideias e crenças diferentes. Dessa forma, a tradução que Mundell (2014) pode apresentar para essa face pode ser vista como: Ajuda com ações, não apenas com palavras. Nesta tradução, podemos pensar no que Lubich diz sobre a vida do Evangelho, que deve ser vivida mais do que pregada. Assim, quando partimos para o concreto - ajudar com ações, seria também este viver com Jesus, mesmo que não seja dito, uma vez que a função dessa tradução é que chegue a todos os funcionários e não apenas aos cristãos. Desta forma, compreendemos que o deslocamento deste enunciado para a tradução cobre mais do que o texto dos dados, tendo acesso a todo um interdiscurso do Movimento dos Focolares.

E finalmente: o Amar reciprocamente e sua tradução como: Construir relacionamentos dia após dia. Temos aqui uma novamente uma mudança do verbo amar para o verbo construir e o objeto desta construção seriam as relações, sendo este um processo contínuo e diário. Compreendemos que o processo de tradução é marcado pelo que Pechêux (1995) entende por gestos de interpretação. O que quer dizer que para que estas escolhas sejam feitas, e um verbo seja apresentado e não outro, um substantivo e não outro, ainda que possam ser entendidas como palavras sinônimas, é necessário que o sujeito se posicione à frente do texto, sendo sempre marcado pelas condições de produção e atravessado pela 
ideologia, que é uma prática e não uma ideia, no entendimento da Análise do Discurso francesa. Essa ação do tradutor seria um gesto de interpretação.

\section{ALGUMAS CONSIDERAÇÕES}

Entendemos que os escritos de Lubich (2017) publicados no livro A Arte de Amar funciona como um arquivo e os seus significados já se encontram estabilizados. E porque Lubich utiliza sempre a teoria clássica da arte, é possível compreender que a sua forma de construir seu pensamento da arte de amar é garantir o acesso a todos, mesmo que as suas condições de produção sejam marcadas pela expressão cultural do movimento dos Focolares. Estas condições permitem ao empresário traduzir a Arte de Amar, deslocando os pontos enumerados por Lubich (2017) para estas condições particulares de produção do mundo empresarial e suas formações discursivas.

No que diz respeito à produção de possíveis efeitos de sentido da tradução proposta pelo Dado das Empresas, entendemos que o tradutor pretende partir do mesmo princípio que Lubich, a revolução, que seria uma mudança, uma passagem de um estado para outro. A partir desta descoberta, voltamos o nosso olhar para a própria tradução, em busca de compreender o significado deste novo texto traduzido. E assim, também compreendemos que o Dado do Amor criado por Lubich para explicar a Arte de Amar às crianças também ecoa na tradução de Mundell (2014) de muitas maneiras.

Assim, a formação discursiva em que se inscreve a Arte de Amar define o que pode e deve ser dito. À luz da teoria discursiva, tais acontecimentos criam o efeito de sentido que gera uma ilusão de permanência de significado, uma repetição apenas da primeira afirmação de Lubich (2017) através de outro meio - os dados.

\section{REFERENCIAS BIBLIOGRÁFICAS}

BENJAMIN, Walter. A tarefa do tradutor, de Walter Benjamin: quatro traduções para o Português. Belo Horizonte: Fale/UFMG, 2008, p.101.

CLÜVER, Claus. Inter textus/inter artes/inter media. Aletria: revista de estudos de literatura, Belo Horizonte, v. 6, p. 11-42, 2006.

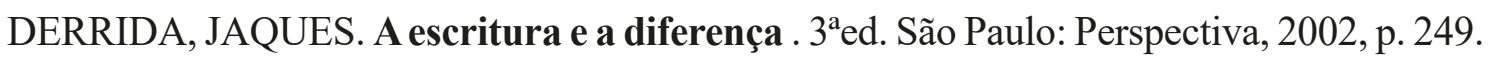
JAKOBSON, ROMAN. On Linguistic Aspects of Translation. In: The Translation studies reader. Ed. Lawrence Venuti. New York, NY: Routledge, 2000, p.138-143.

LEFEVERE, ANDRÉ. Tradução, reescrita e manipulação da fama literária. Bauru: Edusc, 2007, p.264. 
LUBICH, CHIARA. A arte de amar . $3^{\mathrm{a} e d}$. Vargem Grande Paulista -SP: Editora Cidade Nova, 2017, p.143.

MUNDELL, JOHN. The Company Cube: O Dado das Empresas a Nova Revolução para Pequenas Empresas. https://Thecompanycube.Org, p. 8, 2014.

NORD, CHRISTIANE. Functional and Skopos Oriented Approaches to Translation. In: Encyclopedia of Language \& Linguistics. p. 662-665, 2006.

ORLANDI, ENI PUCCINELLI. Discurso e Leitura. São Paulo: Cortez, 2008, 118p.

ORLANDI, ENI PUCCINELLI. Análise de discurso princípios e Procedimentos Campinas: Pontes, 2009, 100p.

PÊCHEUX, MICHEL. Delimitações, Inversões, Deslocamentos. Cadernos de Estudos Linguisticos - UNICAMP, p.7-24, 1990.

PÊCHEUX, MICHEL. Semântica e Discurso: Uma Crítica à Afirmação do Óbvio. $2^{\mathrm{a}} \mathrm{ed}$. Campinas: Editora da UNICAMP, 1995, 278p.

PETRI, VERLI. O funcionamento do movimento pendular próprio às análises discursivas na construção do "dispositivo experimental" da análise de discurso. In: Análise do discurso em perspectiva: teoria, método e análise. Org. PETRI, VERLI, DIAS CRISTIANE. Santa Maria: Ed. da UFSM, P. 39-48, 2013.

PLAZA, JULIO. Tradução intersemiótica. 1ªed. São Paulo: Perspectiva, 2010.

POLCHLOPEK, Silvana Ayub, ZILPSER, Meta Elisabeth, \& COSTA, Maria José R. Damiani. Tradução como ação comunicativa: a perspectiva do funcionalismo nos estudos da tradução. Tradução \& Comunicação. Revista Brasileira de Tradutores, 24, 21-37, 2012.

BENJAMIN, W. A tarefa do tradutor, de Walter Benjamin: quatro traduções para o Português. Belo Horizonte: Fale/UFMG, 2008.

CLÜVER, Claus. Inter textus/inter artes/inter media. Aletria: revista de estudos de literatura, Belo Horizonte, v. 6, p. 11-42, 2006.

DERRIDA, J. (2002). A escritura e a diferença (3rd ed.). São Paulo: Perspectiva.

JAKOBSON, R. (2000). On Linguistic Aspects of Translation. In The Translation studies reader. New York, NY: Routledge.

LEFEVERE, A. (2007). Tradução, reescrita e manipulação da fama literária. Bauru: Edusc. LUBICH, C. (2017). A arte de amar (3 ed.). Vargem Grande Paulista -SP: Editora Cidade Nova. MUNDELL, J. (2014). The Company Cube: O Dado das Empresas a Nova Revolução para Pequenas Empresas. Https://Thecompanycube.Org, p. 8. 
NORD, C. (2006). Functional and Skopos Oriented Approaches to Translation. In Encyclopedia of Language \& Linguistics. https://doi.org/10.1016/B0-08-044854-2/00461-2 ORLANDI, E. P. (2005). Análise de Discurso: princípios e procedimentos. Campinas: Pontes. ORLANDI, E. P. (2008). Discurso e Leitura. São Paulo: Cortez.

ORLANDI, E. P. (2009). Análise de discurso princípios e Procedimentos (p. 100). p. 100. Campinas: Pontes.

PÊCHEUX, M. (1990). Delimitações, Inversões, Deslocamentos. Cadernos de Estudos Linguisticos - UNICAMP, 19(jul./dez.1990), 18.

PÊCHEUX, M. (1995). Semântica e Discurso: Uma Crítica à Afirmação do Óbvio (2 ed.). Campinas: Editora da UNICAMP.

PETRI, V. (2013). O funcionamento do movimento pendular próprio às análises discursivas na construção do "dispositivo experimental" da análise de discurso. In Análise do discurso em perspectiva: teoria, método e análise (p. 312). Santa Maria: Ed. da UFSM.

PLAZA, Julio. Tradução intersemiótica. 1. ed. São Paulo: Perspectiva, 2010.

POLCHLOPEK, S. A., ZILPSER, M. E., \& COSTA, M. J. R. D. (2012). TRADUÇÃO COMO AÇÃO COMUNICATIVA : A PERSPECTIVA DO FUNCIONALISMO NOS. Tradução \& Comunicação Revista Brasileira de Tradutores, 24, 21-37. 